\title{
LA DOCENCIA UNIVERSITARIA EN BUSCA DE IDENTIDAD
}

\section{Isabel CANTÓN MAYO}

Universidad de León

$\mathrm{E}$ s difícil escribir y hasta reflexionar cuando confluyen el corazón y la cabeza en la persona a cuyo homenaje queremos contribuir. Las dudas y los amores se superponen y se abrazan de igual forma en este caso que exige implementar ambos. Así y todo, la reflexión sobre la docencia universitaria que sigue a estas líneas tiene mucho de corazón y menos de razón. Parece que ser docente es algo excelso, algo grande y algo sobre lo que las expectativas de los alumnos y la sociedad son muy altas. Pero descendiendo al terreno aplicado Fernández Pérez (1995) duda que la docencia sea siquiera una profesión y la define como «sacerdocio, función que exige para su ejercicio una fuerte vocación o llamado interno que implica entrega y sacrificio» (Fernández Pérez, 1995: 199 22) es decir la vincula más a una misión o a una vocación. Y es que a diferencia de lo que ha sucedido en la docencia, las ocupaciones que se han convertido en verdaderas profesiones han adoptado modalidades de control profesional en sustitución de las burocráticas (Vaillant, 2007), lo que supone la aplicación de criterios rigurosos, determinados por la propia tarea para la iniciación a la profesión (de forma de asegurar la competencia para el ejercicio profesional) y, además, un control profesional sobre la estructura y el contenido del trabajo (Marcelo, 2011). Para varios autores, la profesionalización está asociada a un desempeño autónomo, con responsabilidad sobre la tarea que se desempeña. Pero estos rasgos no se legislan sino que se construyen a partir de la confluencia de tres elementos: la existencia de un entorno laboral adecuado; una formación inicial y continua de calidad, y una gestión y evaluación que mejore la práctica laboral de los docentes. Consideramos con Day (2007) que la docencia «es una pasión», más que una profesión e incluso que una vocación.

Si la docencia es difícil de encuadrar como profesión, más diversa y difícil es aún definir la identidad de los docentes. Para acercarnos a ello, podemos entender la identidad profesional docente como una evolución o desarrollo gradual de las acciones profesionales que constituyen la especialidad de su oficio, asociada a un sentimiento de competencia en el mismo. En época no muy lejana la identidad de los profesores era relativamente estable, al igual que lo eran las instituciones en las que se realizaba su trabajo. Durante siglos los docentes han construido su identidad profesional basándose en su cualificación y en su pertenencia a una determinada institución educativa. Ello les confería a la 
vez un rol determinado y un estatus socialmente reconocido. Había una forma tradicional de dar clase, el grupo de estudiantes era homogéneo, se transmitían unas normas compartidas y valores comunes, existía su autoridad incontestable y su profesión estaba bien delimitada, así como su identidad como colectivo en el campo social. Ocurría igual con otras profesiones del ámbito de los servicios como la medicina o la justicia. Hoy las profesiones se reconocen y se desenvuelven en un plan identitario dentro de un proceso dinámico e interactivo. La debilidad de las instituciones donde se desenvuelven estas profesiones ha perdido el sentido de aprecio social y deja a los profesionales relativamente solos, lo que les obliga a acciones de desconfianza, de prevención y de defensa propias. La sociedad y la institución donde trabajan representan más obstáculos que hay que superar que lugares donde desenvolver y desarrollar la identidad profesional.

Zabalza (2012) en su libro Profesores y profesión docente: entre el ser y el estar aborda, la identidad profesional señalando que la docencia es más que un trabajo o un empleo coyuntural, inclinándose también por la pasión y la emoción de la misma. Autores como Beijaard et al. (2004) también dudan de la conceptualización de la identidad del profesor como un todo completo y definido. Así al revisar un conjunto de investigaciones sobre identidad profesional especulan como ésta se va reinterpretando a lo largo de su ejercicio profesional, y que sería importante estudiar el efecto de los contextos de trabajo en esta reinterpretación (Vaillant, 2007; Tardif, 2017), aspectos evolutivos coincidentes con el desarrollo de su calidad docente. Day (2011), Lasky (2005) y Astolfi (2003) señalan que el concepto que él profesor construye de sí y de su profesión es una base sobre la cual proyecta su desarrollo y su compromiso con el cambio o mejora educativa.

¿Y qué pasa específicamente con la docencia universitaria? Si nos basamos en el desarrollo profesional docente (DPD) que constituye la evolución profesional más estudiada del profesorado, distinguiríamos cuatro etapas orden de antigüedad: el acceso, la promoción, el asentamiento profesional y la fase de desaceleración. Abordando la primera de ellas, el acceso, hemos de señalar con Barnes (2014) que ser profesor universitario, no sólo ha perdido su categoría social, sino que también ha visto cómo su sueldo ha disminuido de manera inversamente proporcional al del estrés que ha de afrontar, «es uno de los trabajos más tóxicos que existen» en palabras del mismo autor. A pesar de ello la profesión cuenta con aspirantes que, aún con desaliento, se muestran como candidatos al puesto. Todo ello formando parte de una institución cuyas estructuras apenas han evolucionado en siglos. El viacrucis que se ha institucionalizado para acceder a la profesión universitaria pasa por casi una única vía: unirse a un profesor de categoría reconocida (a ser posible catedrático) que te inicie en el mundo académico, dando, a la manera de los viejos gremios, oficio en los dos ámbitos: en el laboral y en el docente e investigador. No hay que olvidar que Rosovsky (1990), el reformador de Harvard, dice que las Universidades aman la jerarquía tanto o más que el ejército y denuncia «la rivalidad, la competitividad, las camarillas de poder o las guerras intestinas». Una beca de formación, una plaza de Profesor Asociado, y la realización de la tesis doctoral forman parte de los prerrequisitos o escalones básicos profesionales. En esta etapa previa las publicaciones, los Congresos, la investigación por concurso público, forman parte del proceso para conseguir la ansiada acreditación. Dos son los entes 
que pueden acreditar para los primeros pasos en la docencia universitaria: la ANECA (Agencia Nacional Española de Calidad) y la ACSUCYL (Agencia Para la Calidad del Sistema Universitario de Castilla y León) amén de las diferentes agencias de calidad, una por autonomía. Las bases de baremación de los méritos tienen tres elementos: docencia, investigación y gestión. Ya la primera, la docencia es un cortafuegos que impide acreditarse para ser profesor a quien no haya impartido antes clase en la Universidad, con lo cual se cierra un círculo para los no iniciados. Con respecto a la investigación, la valoración se basa en publicaciones realizadas y en el impacto de las mismas (número de citas recibidas e indexación de las revistas donde hayan sido publicados los artículos, no sirve publicar libros). El agravante aquí es que un aspirante a profesor universitario tiene dos carencias: no conoce los requisitos de estas revistas, ni su jerarquía, ni puede publicar en ellas sin la ayuda y el apoyo académico, científico y personal de su director de tesis o de los colegas ya asentados. Ello ha creado verdaderos clanes, escuelas, grupos de poder y de presión, ideologizados, o especializados en conseguir que sus protegidos consigan acreditarse mediante intercambio de trabajo por apoyos. Pocos, muy pocos, son los profesores que consiguen por sí mismos la acreditación para ser profesor universitario sin pasar por estos requisitos, aunque algunos lo han conseguido sin integrarse en grupos de investigación, que por otra parte las Universidades fomentan y protegen, bien es verdad que con fines de calidad y no de proselitismo. La acreditación para ingresar en cuerpos universitarios se consigue desde abajo: primero profesor Ayudante; luego profesor Ayudante Doctor, y luego Profesor Contratado Doctor. El paso que abre la vía a la seguridad económica y académica es el siguiente: Profesor Titular de Universidad; con ello se consolida profesionalmente el aspirante. Antes tiene que sufrir un concurso-oposición, que suele ser leve: tres o cinco colegas propuestos por el candidato o por su grupo de investigación, evaluarán su trabajo previo mediante la presentación de un currículum vitae que muestre su preparación, capacidad y dotación para el cargo. A ello se une el Proyecto Académico donde, por escrito debe presentar lo que va a enseñar a sus alumnos de ser declarado apto para el desempeño del puesto de Titular de Universidad con carácter funcionarial. El acceso a la máxima categoría como es la Cátedra queda para un selecto grupo de infatigables, después de la preceptiva acreditación, más de tres sexenios y la posibilidad de plaza de esa categoría en el Área de Conocimiento o en la Universidad.

En un artículo de divulgación señalábamos (Cantón, 2015) que en la Universidad existen dos tipos de profesores: los conspiradores y los investigadores, y que les va mejor a los primeros. Así mientras los primeros toman mucho café, se reúnen mucho, hablan constantemente por teléfono y buscan la manera de acceder a los puestos de libre designación, que les gratifican de tres formas: con poder, con sueldo y con méritos; los segundos, los investigadores, se queman las pestañas en el ordenador, leen, se relacionan poco, tienen contactos con otros colegas, y escriben artículos que sólo les retribuyen con méritos y no siempre. Un estudio de la Universidad de Murcia (Buendía, y otros, 2009) pusieron de manifiesto que el $83 \%$ del profesorado universitario sufre estrés crónico y el $44 \%$ sufre acoso laboral. Con ser muy preocupantes estos datos que muestran la permanente lucha por la consolidación del puesto y la permanencia en el mismo, consideramos que la docencia universitaria tiene también aspectos compensatorios que la hacen atractiva: posición social, 
capacidad de influencia y de formación de otros profesionales, vocación, aspectos emocionales y satisfacción personal que en una escala de 10 se muestra en 7-8.

Volviendo pues a la identidad profesional docente señalar que no se forja sólo por el conjunto de conocimientos pedagógicos, disciplinares y académicos adquiridos en los procesos de formación. La identidad profesional es también producto de las condiciones en las que se da el ejercicio profesional, es decir, el contexto (Day, et al., 2006). A este respecto hay investigaciones que se han interesado por comprender las relaciones entre variables del contexto y la satisfacción laboral del profesor. En el trabajo de Skaalvik y Skaalvik (2011) consideran seis dimensiones correlacionadas con el agotamiento emocional como indicador de la satisfacción laboral: la congruencia existente entre los valores personales e institucionales, el apoyo de los directivos, la relaciones con otros profesores y los padres de familia, la presión de tiempo y los problemas de disciplina. En un trabajo anterior (Cantón y Téllez, 2016) encontramos que los factores más satisfactorios para el profesorado estaban en la propia realización diaria del trabajo, en el lugar de trabajo y en la entrega personal al trabajo. Todos estos indicadores se encuentran enmarcados en la dimensión más vocacional e identitaria de la profesión por lo que consideramos que les gratifica la realización del trabajo por encima de cuestiones varias que son de índole menor. Coincidiendo con otras investigaciones citadas, se observó insatisfacción en los docentes en aspectos como: el grado de estrés experimentado, el tiempo disponible para el trabajo personal, la ayuda proporcionada por la administración para solucionar los problemas, la posibilidad de uso de TIC. En el nivel diacrónico los profesores hoy están menos satisfechos que hace unos años cuando se inició la crisis económica en nuestro país, y se muestran insatisfechos con la posibilidad de formarse con la ayuda de la administración y como vimos se aprecia cierto porcentaje que experimenta ansiedad en su desempeño profesional.

Uno de los autores más relevantes sobre el tema (Tardif, 2017), se pregunta cómo définir la identidad profesional de los docentes y señala algunas perspectivas para abordarla como su competencia, su poder, su lugar en la organización, su pertenencia a la Administración del Estado o a entidades privadas y su prestigio social. Por su parte Day (2006: 191) pone el foco identitario en la emancipación y en la pasión por enseñar y señala que «su función emancipadora consiste en influir en la capacidad de los alumnos para entusiasmarse con el aprendizaje, en ayudarles a elevar su mirada más allá de lo inmediato, y aprender más sobre sí mismos, en construir una identidad basada en autoimágenes nuevas». Prieto Parra (2004) señala una construcción identitaria evolutiva desde la formación, colegiada, compartida, reflexiva y autoconstruida responsablemente. A ello se une el hecho de que la identidad docente es un sistema complejo y los sistemas complejos se entienden como conjunto de elementos en interacción por lo que son aquellos sistemas cuyo comportamiento no puede explicarse mediante el análisis de sus componentes de manera aislada, es decir, obviando las interacciones entre sus partículas fundamentales. Para terminar nos referimos a las interacciones que señalan los big data, esta joven disciplina científica que proporciona un nuevo enfoque al estudio de cualquier sistema cuyos componentes estén organizados en red. Dubar (2002) define la identidad como «el resultado a la vez estable y provisional, individual y colectivo, subjetivo y objetivo, biográfico y 
estructural, de los diversos procesos de socialización que, conjuntamente, construyen los individuos y definen las instituciones». Otros estudios sobre identidad (Giddens, 1995; Holstein \& Gubrium, 2000; Gergen, 1998) o Ricoeur, 1991, 1996) coinciden en señalar que la identidad docente es evolutiva y dinámica, no estática.

En síntesis, asumimos que la identidad profesional es una construcción que se realiza a lo largo de la vida del profesor, en sucesivas etapas y eventos complejos de clasificar, y que el concepto que el profesor construye de sí como profesional integra dimensiones afectivas, cognitivas, sociales en una constante proyección al pasado y al futuro (Galaz, 2011). Por ello coincidimos en señalar que la identidad profesional del docente universitario es en buena medida una profesión ocasional y circunstancial que se complementa con un proceso de interpretación de uno mismo como cierta clase de persona y de autorreconocimiento en un contexto en desarrollo de la actividad profesional (Caballero y Bolívar, 2015).

Como específico de la profesión universitaria encontramos únicamente en los niveles más cualificados y más altos profesionalmente, cierta dosis de engolamiento y autoestima, relacionados con la dificultad del proceso de acceso y tránsito por las diferentes categorías universitarias. No es de despreciar, en este sentido tampoco las llamadas escuelas que en algunas áreas de conocimiento ejercen un férreo control identitario, ideológico y social en los momentos de acceso. Por ello, la identidad de los docentes universitarios sigue en proceso de búsqueda y sometida a los vaivenes de la sociedad, de la universidad, de los grupos de presión, de la Administración y de otros factores más personales y contextuales.

Para concluir, señalamos la dificultad de la construcción de la identidad profesional del docente universitario, su particularidad y variabilidad determinadas por las circunstancias, el acceso, el contexto, el grupo social y la propia institución. Consideramos, pues la identidad docente del profesor universitario como una amalgama de circunstancias personales, sociales, contextuales, económicas, etc. que dan como resultado un ser personal particular, variable y evolutivo.

\section{Bibliografía}

Astolfi, J. (2003): Éducation et formation: nouvelles questions, nouveaux métiers. ESF Editeur: IssyLes-Moulineaux.

Barnés, H. G. (2014): «Los 8 males del profesor universitario: “es uno de los trabajos más tóxicos que existen"», en http://www.elconfidencial.com/alma-corazon-vida/2014-07-07/los-8-males-delprofesor-universitario-es-uno-de-los-trabajos-mas-toxicos-que-existen_156018/ Consulta Agosto 2017.

BeijaArd, D., MeiJer, P. Y Verloop, N. Jan D. (2004): «Reconsidering research on teacher professional identity», Teaching and Teacher Education, 20/2, pp. 107-128.

BuEndíA, L. y otros (2009): Competencias científicas para realizar una tesis doctoral. Barcelona, Davincicontinental. 
Caballero, K. \& Bolívar, A. (2015): «Identidades profesionales, concepciones de enseñanzaaprendizaje y estrategias docentes del profesorado universitario», REDU. Revista de Docencia Universitaria, 13/1, pp. 57-77.

CAntón Mayo, I. (2015): «Palabras de homenaje al profesor Manuel Lorenzo Delgado de la Universidad de Granada», Enseñanza \& Teaching: Revista interuniversitaria de didáctica, 33/2, 2015, pp. 33-34.

CANTÓN, I. \& TÉLlEZ, S. (2016): «La satisfacción laboral y profesional de los profesores», Revista Lassalista de Investigación, 13/1, pp. 214-226.

DAY, C. (2006): Pasión por enseñar. La identidad personal y profesional del docente y sus valores. Madrid, Narcea.

Dubar, C., TriPIER, P. ET Boussard, V. (2011): Sociologie des professions. Paris, Armand Colin.

DUBAR, C. (2002): La crisis de las identidades. La interpretación de una mutación. Barcelona, Bellaterra [La crise des identités. L'interprétation d'une mutation. Paris, PUF, 2000].

FERNÁNDEZ PÉREZ, M. (1995): La profesionalización del docente. Perfeccionamiento, investigación en el aula, análisis de la práctica. Madrid, Siglo XXI.

Galaz, A. (2011): «El profesor y su identidad profesional ¿facilitadores u obstáculos del cambio educativo?», Estudios Pedagógicos, XXXVII/2, pp. 89-107.

GERGEN, K. (1998): Organizational science in a postmodern context. Yale University.

GIDDENS, A. (1995): Modernidad e identidad del yo: el yo y la sociedad en la época contemporánea. Barcelona, Península. [Modernity and self-identity. Self and society in the late modern age Cambridge, Polity Press, 1991].

HoldSTEIN J.A. Y GUBRUM, J.F. (2000): Analyzing interpretative practice. En Denzin yLincolm. The reality of etnomethodology. Wiley Nueva York.

LASKY, S. (2005): «A Sociocultural approach to understanding teacher identity, agency and professional vulnerability in a context of secondary school reform», Teaching and Teacher Education 21/8, pp. 899-916.

MARCELO, C. (2011) (Coord.): Evaluación del desarrollo profesional docente. Barcelona, Davinci, pp. 151-171.

PRIETO PARRA, M. (2004): «La construcción de la identidad profesional del docente: un desafío permanente», en Revista enfoques educacionales 6/1, pp. 29-49.

RicOeUR, P. (1991): Narrative identity. Philosophy Today, 35 (spring), pp. 73-81. (1996): Sí mismo como otro. Madrid, Siglo XXI. [Soi-même comme un autre. Paris, Éditions du Seuil, 1990].

Rosovsky, H. (1990): The Universityan Owners Manual. Harvard University.

SkaAlviK, E. M., \& SkaAlviK, S. (2011): «Job Satisfaction, Stress and Coping Strategies in the Teaching Profession—What Do Teachers Say?», International Education Studies, 8/3, pp. 181192. 
(2011): «Teacher job satisfaction and motivation to leave the teaching profession: Relations with school context, feeling of belonging, and emotional exhaustion», Teaching and Teacher Education, 27/6, pp. 1029-1038.

TARDIF, M. (2006): Los saberes del docente y su desarrollo profesional. Madrid, Narcea.

- (2017): «Los profesores en Canadá: ¿una identidad profesional en mutación?», en Cantón y Tardif: Identidad profesional del profesorado. En prensa.

TARDIF, M.; Borges, C., Y MALO, A. (2012): Le virage reflexif en éducation. Dù en sommes-nous 30 ans après Schön ? Belgique, De Boeck.

Vaillant, D. (2007): La identidad docente. Congreso Internacional «Nuevas Tendencias en la Formación Permanente del Profesorado». Barcelona, GTD-PREAL-ORT.

ZABAlZA, M. A. (2012): Profesores y profesión docente: entre el ser y el estar. Madrid, Narcea. 